$\stackrel{N / N}{=}$

Global burnals Inc.

की
GLOBAL JOURNAL OF MEDICAL RESEARCH: D

RADIOLOGY, DIAGNOSTIC AND INSTRUMENTATION

Volume 20 Issue 1 Version 1.0 Year 2020

Type: Double Blind Peer Reviewed International Research Journal

Publisher: Global Journals

Online ISSN: 2249-4618 \& Print ISSN: 0975-5888

\title{
Observational and Comparative Study of Utility of Transabdominal Ultrasound in Diagnosis of Mild Acute Gastritis
}

By Dr. Vikas Leelavati Balasaheb Jadhav, Dr. S. G. Gandage, Dr. Sanjay M. Khaladkar \& Dr. Rajesh S. Kuber

Dr. D.Y. Patil Medical College \& Research Centre Abstract-Background: Inflammation of the gastric mucosa is gastritis. It may be acute or chronic. It usually affects half of the world population. Acute gastritis is caused by medications, like, NSAID (Nonsteroidal Anti-Inflammatory Drugs) and Corticosteroids, viral infection, extreme stress, etc.

Aim and Objectives: To assess/evaluate the role of transabdominal ultrasound as an imaging modality for the diagnosis of acute gastritis and to study patterns of involvement of various layers of the stomach wall.

Materials and Methods: The thickness of the whole Stomach wall and individual layers were calculated in 20 normal individuals (Control) and 20 Patients of Gastritis, confirmed later on Endoscopy. Endoscopy was performed on the same or the next day after the Sonography.

Keywords: acute gastritis, gastric erosion, mucosal erosions, mucosal thickness, layers, gut signature, sonography, ultrasound, gastric wall, stomach.

GJMR-D Classification: NLMC Code: WN 180

Strictly as per the compliance and regulations of:

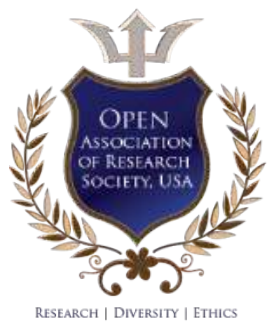

(C) 2020. Dr. Vikas Leelavati Balasaheb Jadhav, D r. S. G. Gandage, Dr. Sanjay M. Khaladkar \& Dr. Rajesh S. Kuber. This is a research/review paper, distributed under the terms of the Creative Commons Attribution-Noncommercial 3.0 Unported License http://creativecommons.org/licenses/by-nc/3.0/), permitting all non-commercial use, distribution, and reproduction in any medium, provided the original work is properly cited. 


\title{
Observational and Comparative Study of Utility of Transabdominal Ultrasound in Diagnosis of Mild Acute Gastritis
}

\author{
Dr. Vikas Leelavati Balasaheb Jadhav ${ }^{\alpha}$, Dr. S. G. Gandage ${ }^{\sigma}$, Dr. Sanjay M. Khaladkar ${ }^{\circ}$ \\ \& Dr. Rajesh S. Kuber ${ }^{\omega}$
}

\begin{abstract}
Background: Inflammation of the gastric mucosa is gastritis. It may be acute or chronic. It usually affects half of the world population. Acute gastritis is caused by medications, like, NSAID (Nonsteroidal Anti-Inflammatory Drugs) and Corticosteroids, viral infection, extreme stress, etc.
\end{abstract}

Aim and Objectives: To assess/evaluate the role of transabdominal ultrasound as an imaging modality for the diagnosis of acute gastritis and to study patterns of involvement of various layers of the stomach wall.

\begin{abstract}
Materials and Methods: The thickness of the whole Stomach wall and individual layers were calculated in 20 normal individuals (Control) and 20 Patients of Gastritis, confirmed later on Endoscopy. Endoscopy was performed on the same or the next day after the Sonography.
\end{abstract}

Results: There was thickening of layer 2 (muscularis mucosa) in the Mild acute gastritis. Thickening of Layers 1 and 2 and total gastric wall thickness was statistically significant. The ratio of the thickness of Layer 2 to a total Gastric wall thickness was statistically significant. These observations indicate that transabdominal Ultrasound with convex probe, followed by linear probe can predict gastritis and can reduce the number of endoscopic evaluations and further ulcer formations. It can also predict associated mucosal erosions if layer 1 thickness is less than $1 \mathrm{~mm}$ with associated thickening of layer 2 .

Keywords: acute gastritis, gastric erosion, mucosal erosions, mucosal thickness, layers, gut signature, sonography, ultrasound, gastric wall, stomach.

\section{InTRODUCTION}

nflammation of the gastric mucosa is gastritis. Depending on the duration, it can be acute or chronic. It usually presents with nausea, vomiting, bloating, loss of appetite, burning pain in the epigastric region and unexplained weight loss. It usually affects half of the

Author a: Clinical Research Scientist, Department of Radio Diagnosis, Dr. D. Y. Patil Medical College and Research Centre, Dr. D. Y. Patil Vidyapeeth, Pimpri, Pune. e-mail: drvikasjadhav@gmail.com

Author o: Professor, Department of Radio Diagnosis, Dr. D. Y. Patil Medical College and Research Centre, Dr. D. Y. Patil Vidyapeeth, Pimpri, Pune. e-mail: dr.siddappagandage@gmail.com

Author p: Professor, Department of Radio Diagnosis, Dr. D. Y. Patil Medical College and Research Centre, Dr. D. Y. Patil Vidyapeeth, Pimpri, Pune.e-mail: drsanjaymkhaladkar@gmail.com

Author w: Professor and Head of the Department, Department of Radio Diagnosis, Dr. D. Y. Patil Medical College and Research Centre, Dr. D. Y. Patil Vidyapeeth, Pimpri, Pune.

e-mail:dr.rajeshkuber@gmail.com world population. Acute gastritis is caused by medications, like NSAID (Nonsteroidal Anti-Inflammatory Drugs) and corticosteroids, bacterial infections $(\mathrm{H}$. Pylori), excessive alcohol consumption, viral infection, extreme stress, systemic stress, bile reflux, surgery, ingestion of corrosive substances, kidney failure, ICU Patients on Ventilator, autoimmune diseases affecting the stomach mucosa (autoimmune gastritis), Crohn's Disease, spicy foods, radiation, vasculitis, etc. ${ }^{1}$

Histologically, it is characterized by infiltration of the mucosa of gastric body and antrum with granulocytes. Pangastritis refers to inflammation of the entire stomach. German Physician George Ernst Stahn in 1728, first coined the term Gastritis. Charles and Handfield Jones and Wilson Fox, in 1854, first described microscopic changes of stomach mucosa in diffuse and segmental forms of gastritis. British physician William Brinton in 1859, first described acute, subacute and chronic gastritis. Italian Anatomical pathologist Giovanni Battista Morgagni first described characteristics of gastric inflammation - erosive gastritis and ulcerative gastritis. $^{2}$

\section{il. Material and Method}

\section{a) Aim and Objective}

This study aimed to determine the signs of Mild Acute Gastritis on TransAbdominal Ultrasound.

\section{b) Material and Method}

Sonographic evaluation of the stomach was performed by an experienced Sonologist using a convex (3-5 MHz) probe, followed by a linear transducer (7-12 $\mathrm{MHz}$ ) after obtaining Oral Informed Consent. (Figures 1, 2)

The patient was administered water for gastric distension (between 200 to $1000 \mathrm{ml}$ depending upon capacity and without causing nausea), stomach wall was evaluated in the body and antrum, after adequate gastric distension.

The patient was initially examined in the supine position, followed by the right lateral decubitus position.

The Transducer was kept in the Epigastric region, initially in the Transverse plane and fluid filled stomach was identified. Then the Probe was placed in the sagittal plane and the stomach body and antrum 
were evaluated by shifting the transducer from left to right.

The multilayered wall of the stomach was best seen in the parasagittal plane, just on the right side of the midline, using the left hepatic Lobe as an acoustic window. (Figures 3, 4).

Fluid-filled stomach was seen between left hepatic lobe and caudate lobe anteriorly and pancreas posteriorly.

Whole Stomach wall thickness and thickness of individual layers (S1-S5), was measured in the crosssection, in the longitudinal section at the level of superior mesenteric Artery.

The thickness of the whole stomach wall and individual layers were calculated in 20 normal individuals (control) and 20 patients of gastritis, confirmed later on endoscopy. Endoscopy was performed on the same or the next day after the Sonography. The results of the direct mucosal inspection on Endoscopy were documented and Biopsy was obtained from the involved area.

Pathologist examined the presence of Gastritis. On histopathology, none of the patients had other illnesses than gastritis. Pathologic findings were used as a gold standard to evaluate the ultrasound findings.

\section{Study Design}

The thickness of the whole Stomach wall and individual layers were calculated in 20 Normal individuals (Control) and 20 Patients of Gastritis, confirmed later on Endoscopy.

Exclusion criteria were-Simple Obesity (Body Mass Index more than or equal to $25 \mathrm{~kg} / \mathrm{m} 2$ ), previous history of gastric surgeries, abdominal surgeries, abdominal radiotherapy, suspected cases of Acute Pancreatitis, Acute Cholecystitis, and Abdominal Malignancy.

Fasting guidelines (Strict nil by mouth 8 hours before sonography) were applied.

Demographic Age, Sex, BMI, Smoking, Alcohol consumption and ingestion of NSAID were recorded.

Our research included both the Pediatric and Adult populations.

The thickness of gastric layers on ultrasound are labeled as (Figures 3,4)

S1-Mucosa.

S2-Muscularis mucosa

S3-Submucosa

S4-Muscularis propria

\section{S5-Serosa}

\&

Whole wall thickness in the gastric antrum.

The thickness of individual layers- Layer 1, Layer 2, Layer 3, Layer 4, Layer 5, total The thickness of Gastric wall (including layers 1 to 5), were obtained in 20 Controls (normal) and 20 patients of gastritis. The ratio of Layer 2 to the full the thickness of the gastric wall was obtained in Controls and Patients of Gastritis.

\section{Results}

Table 1: Control Group

\begin{tabular}{|c|c|c|c|c|c|c|c|c|}
\hline Sr. No & $\begin{array}{c}\text { Layer } \\
1\end{array}$ & $\begin{array}{c}\text { Layer } \\
2\end{array}$ & $\begin{array}{c}\text { Layer } \\
3\end{array}$ & $\begin{array}{c}\text { Layer } \\
\mathbf{4}\end{array}$ & $\begin{array}{c}\text { Layer } \\
5\end{array}$ & $\begin{array}{c}\text { Layer } \\
1+2\end{array}$ & $\begin{array}{c}\text { Total } \\
\text { wall } \\
\text { thickn } \\
\text { ess }\end{array}$ & $\begin{array}{c}\text { Layer 2/Total } \\
\text { Wall } \\
\text { thickness }\end{array}$ \\
\hline 1 & 1 & 1 & 2 & 2 & 1 & 2 & 7 & 0.142857143 \\
\hline 2 & 1 & 1.1 & 2 & 2 & 1 & 2.1 & 7.1 & 0.154929577 \\
\hline 3 & 1 & 1 & 2.1 & 2 & 1 & 2 & 7.1 & 0.14084507 \\
\hline 4 & 1 & 0.9 & 2.1 & 2 & 1 & 1.9 & 7 & 0.128571429 \\
\hline 5 & 1 & 1 & 2 & 2 & 1 & 2 & 7 & 0.142857143 \\
\hline 6 & 1 & 1.1 & 2.2 & 2 & 1 & 2.1 & 7.3 & 0.150684932 \\
\hline 7 & 1 & 1.1 & 2.3 & 2 & 1 & 2.1 & 7.4 & 0.148648649 \\
\hline 8 & 1 & 1 & 2.1 & 2 & 1 & 1.9 & 7.2 & 0.138888889 \\
\hline 9 & 1 & 0.9 & 2 & 2 & 1 & 1.9 & 6.9 & 0.130434783 \\
\hline 10 & 1 & 1 & 2.1 & 2 & 1 & 2 & 7.1 & 0.14084507 \\
\hline 11 & 1 & 1.1 & 2.2 & 2 & 1 & 2.1 & 7.3 & 0.150684932 \\
\hline 12 & 1 & 1 & 2 & 2 & 1 & 2 & 7 & 0.142857143 \\
\hline 13 & 1 & 1 & 2 & 2 & 1 & 2 & 7 & 0.142857143 \\
\hline 14 & 1 & 0.9 & 2.1 & 2 & 1 & 1.9 & 7 & 0.128571429 \\
\hline 15 & 1 & 1 & 2.1 & 2 & 1 & 2 & 7.1 & 0.14084507 \\
\hline 16 & 1 & 1 & 2.4 & 2 & 1 & 2 & 7.4 & 0.135135135 \\
\hline & & & & & & & & \\
\hline
\end{tabular}




\begin{tabular}{|c|c|c|c|c|c|c|c|c|}
\hline 18 & 1 & 1 & 2.3 & 2 & 1 & 2 & 7.3 & 0.136986301 \\
\hline 19 & 1 & 1.1 & 2 & 2 & 1 & 2.1 & 7.1 & 0.154929577 \\
\hline 20 & 1 & 1 & 2 & 2 & 1 & 2 & 7 & 0.142857143 \\
\hline
\end{tabular}

Table 2: Study Patient Group

\begin{tabular}{|c|c|c|c|c|c|c|c|c|c|}
\hline $\begin{array}{c}\text { Sr. } \\
\text { No }\end{array}$ & $\begin{array}{c}\text { Layer } \\
1\end{array}$ & $\begin{array}{c}\text { Layer } \\
2\end{array}$ & $\begin{array}{c}\text { Layer } \\
3\end{array}$ & $\begin{array}{c}\text { Layer } \\
\mathbf{4}\end{array}$ & $\begin{array}{c}\text { Layer } \\
5\end{array}$ & $\begin{array}{c}\text { Layer } \\
1+2\end{array}$ & $\begin{array}{c}\text { Toyer All } \\
\text { wall } \\
\text { thickness }\end{array}$ & $\begin{array}{c}\text { Layer } \\
2+3\end{array}$ & $\begin{array}{c}\text { Layer 2/Total } \\
\text { Wall } \\
\text { thickness }\end{array}$ \\
\hline 1 & 1 & 2 & 2 & 2 & 1 & 3 & 8 & 4 & 0.25 \\
\hline 2 & 1 & 3 & 2.1 & 2 & 1 & 4 & 9.1 & 5 & 0.32967033 \\
\hline 3 & $<1$ & 2 & 2 & 2 & 1 & 3 & 8 & 4 & 0.25 \\
\hline 4 & 1 & 2 & 2.2 & 2 & 1 & 3 & 8.2 & 4 & 0.243902439 \\
\hline 5 & $<1$ & 3 & 2 & 2 & 1 & 4 & 9 & 5 & 0.33333333 \\
\hline 6 & 1 & 3 & 2 & 2 & 1 & 4 & 9 & 5 & 0.33333333 \\
\hline 7 & 1 & 2 & 2.2 & 2 & 1 & 3 & 8.2 & 4 & 0.243902439 \\
\hline 8 & 1 & 2 & 2 & 2 & 1 & 3 & 8 & 4 & 0.25 \\
\hline 9 & $<1$ & 3 & 2.3 & 2 & 1 & 4 & 9.3 & 5 & 0.322580645 \\
\hline 10 & 1 & 2 & 2 & 2 & 1 & 3 & 8 & 4 & 0.25 \\
\hline 11 & 1 & 2 & 2 & 2 & 1 & 3 & 8 & 4 & 0.25 \\
\hline 12 & 1 & 3 & 2.1 & 2 & 1 & 4 & 9.1 & 5 & 0.32967033 \\
\hline 13 & 1 & 2 & 2 & 2 & 1 & 3 & 8 & 4 & 0.25 \\
\hline 14 & $<1$ & 3 & 2 & 2 & 1 & 4 & 9 & 5 & 0.333333333 \\
\hline 15 & 1 & 2 & 2.1 & 2 & 1 & 3 & 8.1 & 4 & 0.24691358 \\
\hline 16 & 1 & 3 & 2 & 2 & 1 & 4 & 9 & 5 & 0.333333333 \\
\hline 17 & $<1$ & 3 & 2 & 2 & 1 & 4 & 9 & 5 & 0.333333333 \\
\hline 18 & 1 & 3 & 2 & 2 & 1 & 4 & 9 & 5 & 0.333333333 \\
\hline 19 & 1 & 3 & 2.2 & 2 & 1 & 4 & 9.2 & 5 & 0.326086957 \\
\hline 20 & 1 & 2 & 2 & 2 & 1 & 3 & 8 & 4 & 0.25 \\
\hline
\end{tabular}

Chi Square $=0.04228 ; p$-value $=>0.9999999$

In Control group (Figures 3, 4)

- The thickness of Layer 1 was $1 \mathrm{~mm}$,

- The thickness of Layer 2 was 0.9 to $1.1 \mathrm{~mm}$

- The thickness of Layer 3 was $2 \mathrm{~mm}$ to $2.4 \mathrm{~mm}$

- The thickness of Layer 4 was $2 \mathrm{~mm}$

- The thickness of Layer 5 was $1 \mathrm{~mm}$

- $\quad$ The Combined thickness of Layer 1 and 2 was 1.9 to $2.1 \mathrm{~mm}$.

- Total thickness of the Gastric wall (Layer 1-5) was $6.9 \mathrm{~mm}$ to $7.4 \mathrm{~mm}$.

- Ratio of the thickness of Layer 2 to total wall thickness was 0.12 to 0.15

In Acute Mild Gastritis group- (Figures 5, 6)

- The thickness of Layer 1 was $1 \mathrm{~mm}$,

- In 5 cases of Gastric erosion (Proved on Endoscopy) The thickness of Layer 1 was less than $1 \mathrm{~mm}$
- $\quad$ The thickness of layer 2 was 2 to $3 \mathrm{~mm}$

- $\quad$ The thickness of layer 3 was $2 \mathrm{~mm}$ to $2.3 \mathrm{~mm}$

- $\quad$ The thickness of layer 4 was $2 \mathrm{~mm}$

- $\quad$ The thickness of layer 5 was $1 \mathrm{~mm}$

- $\quad$ The combined thickness of layer 1 and 2 was 3-4 $\mathrm{mm}$.

- Total thickness of the Gastric wall (layer 1-5) was 8 $\mathrm{mm}$ to $9.2 \mathrm{~mm}$.

- Ratio of the thickness of Layer 2 to the total gastric wall thickness was 0.25 to 0.33

Thus, in Patients of Mild Gastritis, there was thickening of layer 2 .

Thickening of Layers 1 and 2 and total gastric wall thickness was statistically significant. Ratio of the thickness of Layer 2 to a total Gastric wall thickness was statistically significant.

Ultrasound findings of gastritis were confirmed on gastroscop y examination (Figure7). 


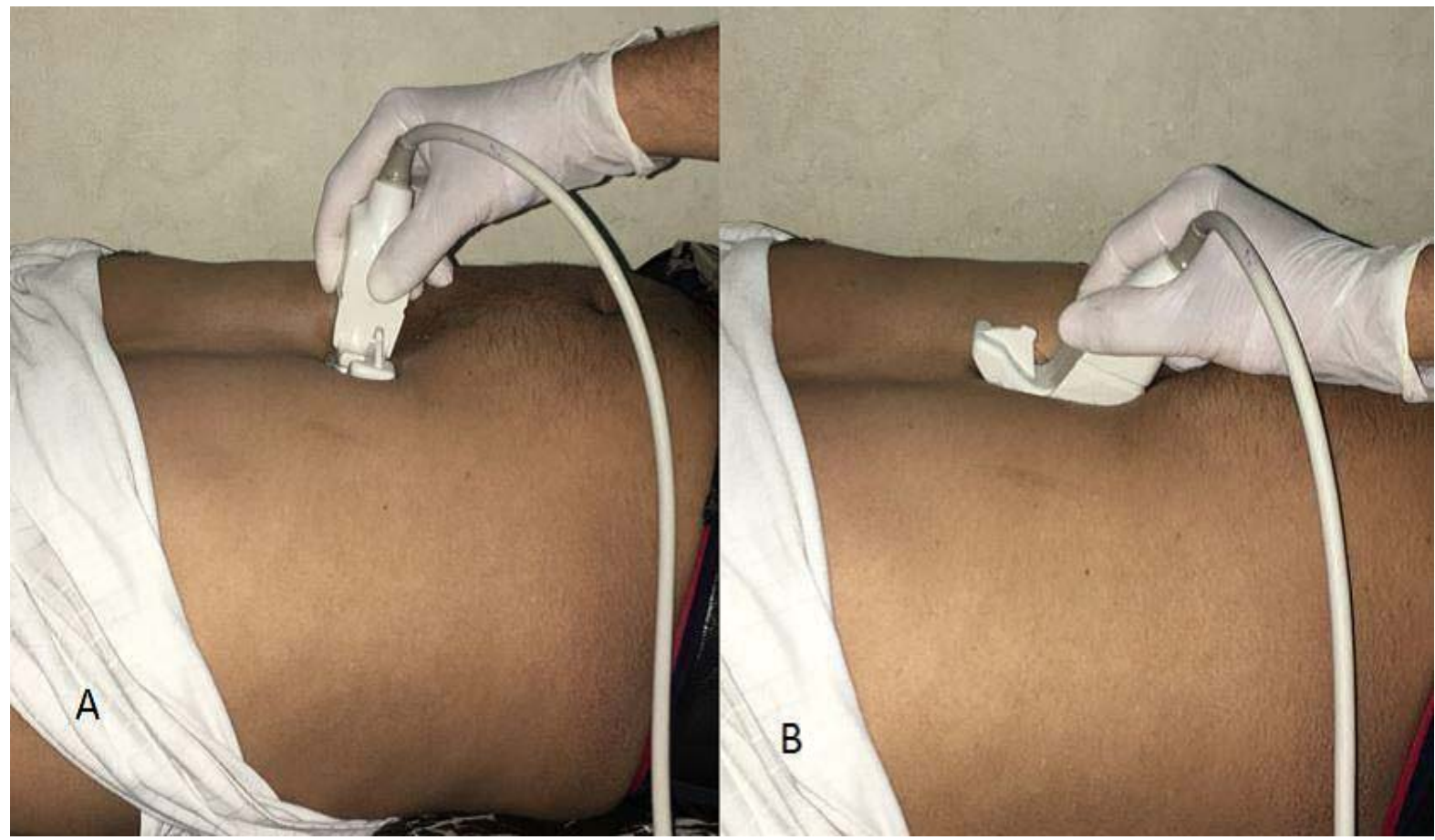

Figure 1: Ultrasound scanning with Convex Probe showing the position of the Convex probe in the epigastric region, in transverse (A) and in longitudinal (B) plane

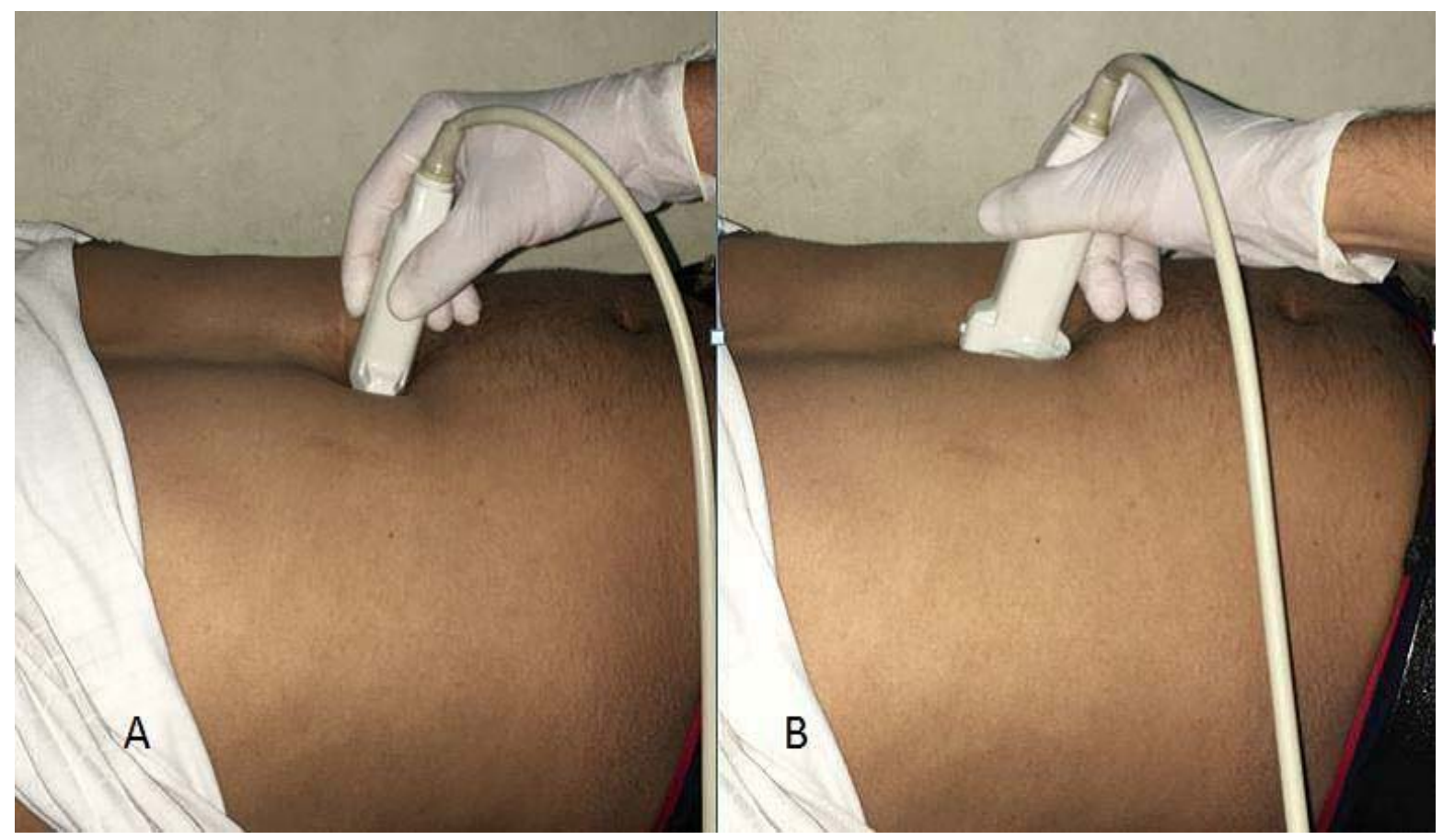

Figure 2: Ultrasound scanning with Linear Probe showing the position of the Linear probe in the epigastric region, in transverse (A) and in longitudinal (B) plane 


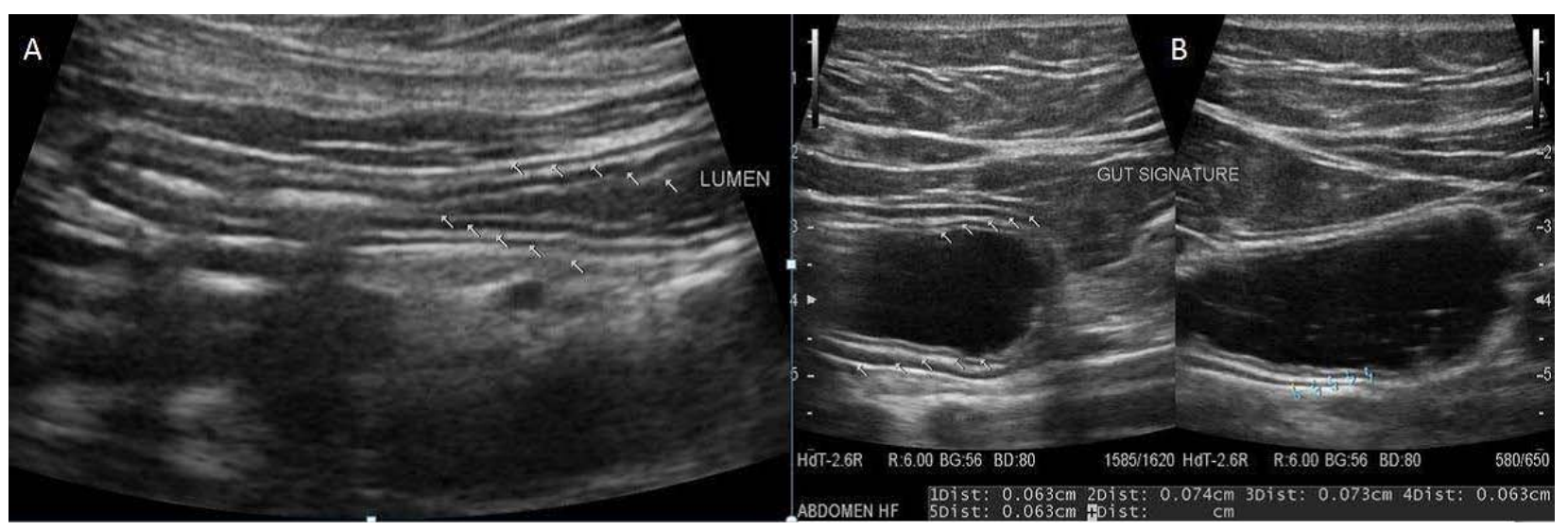

Figure 3: Ultrasound with the Convex Probe showing Layers of Stomach wall

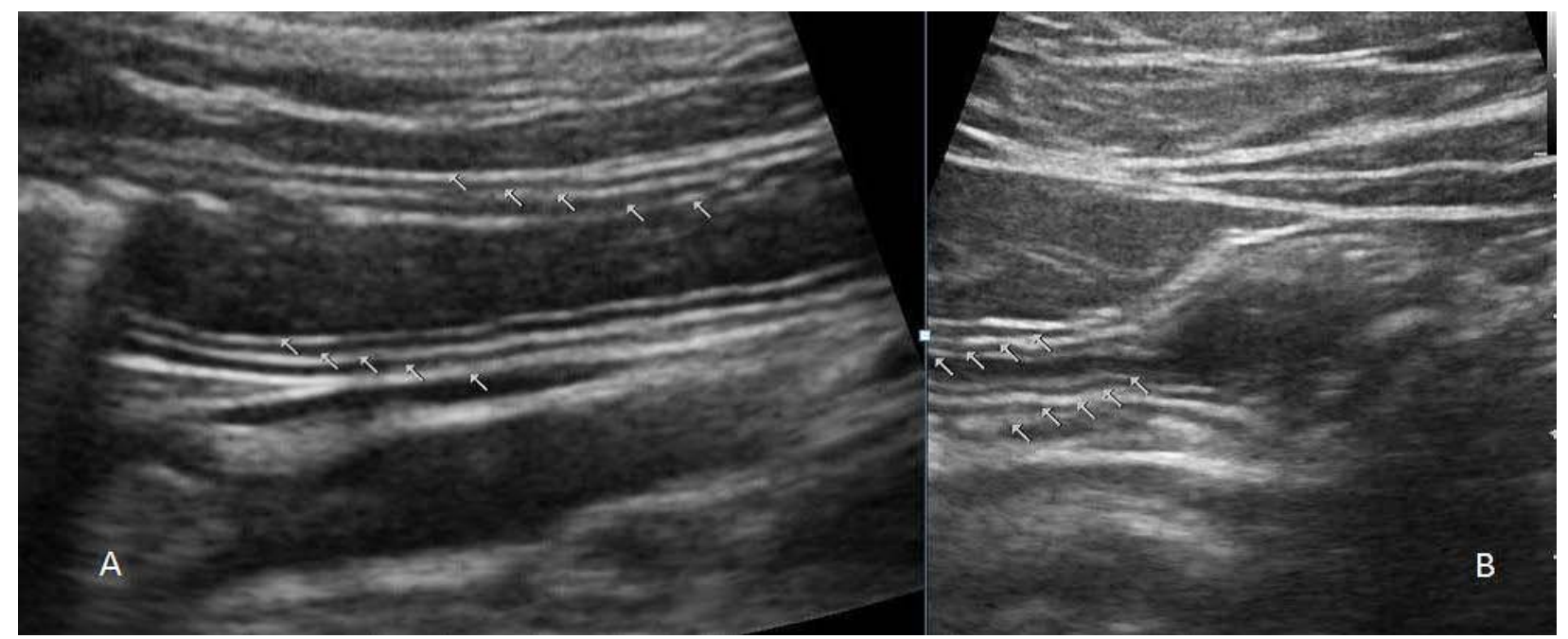

Figure 4: Ultrasound with the Linear Probe showing Layers of Stomach wall
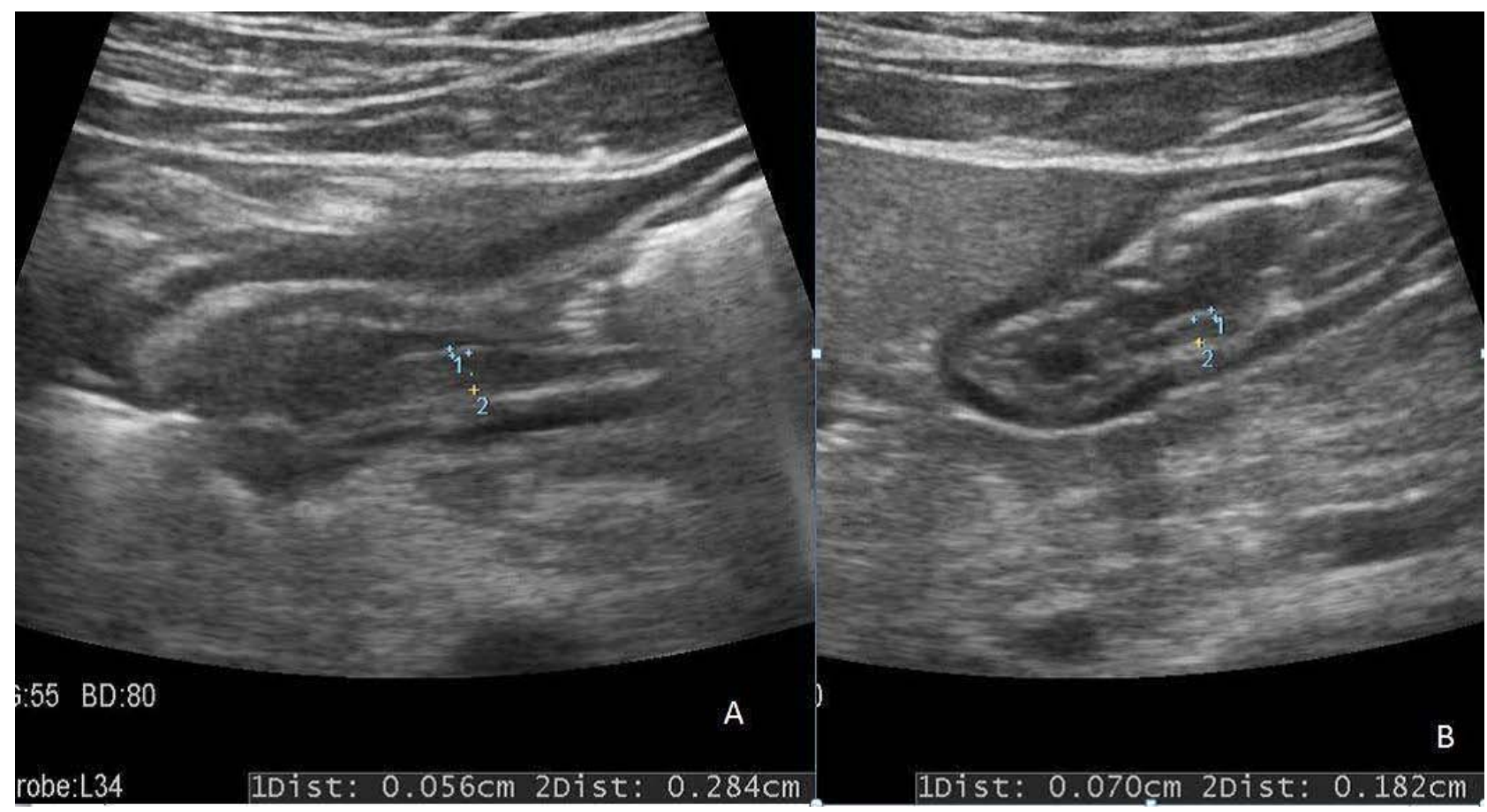

Figure 5: Ultrasound with the Convex Probe showing thickening of Layer 2 of Stomach in Mild Acute Gastritis 


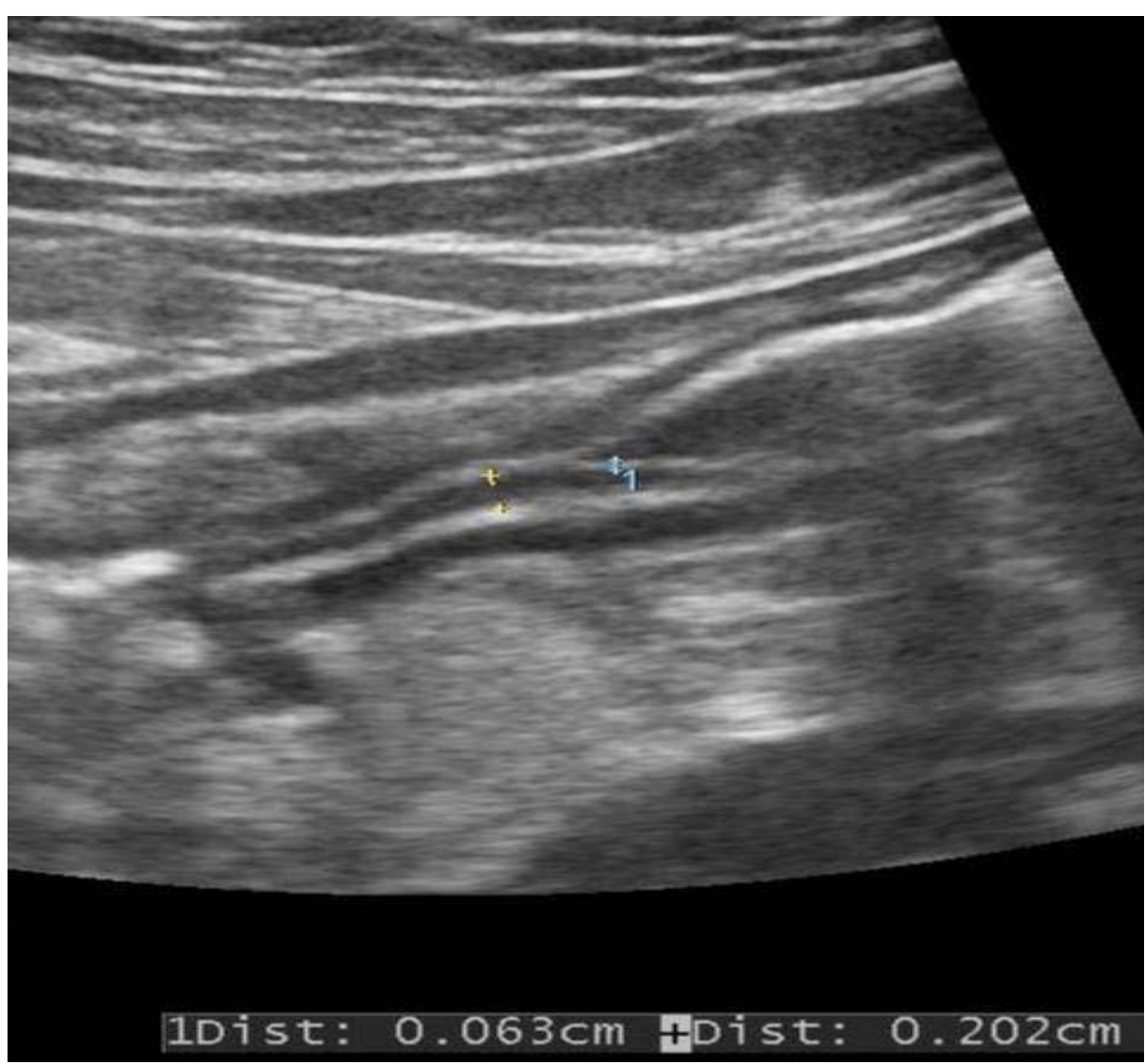

Figure 6: Ultrasound with Linear Probe showing thickening of Layer 2 of Stomach in Mild Acute Gastritis

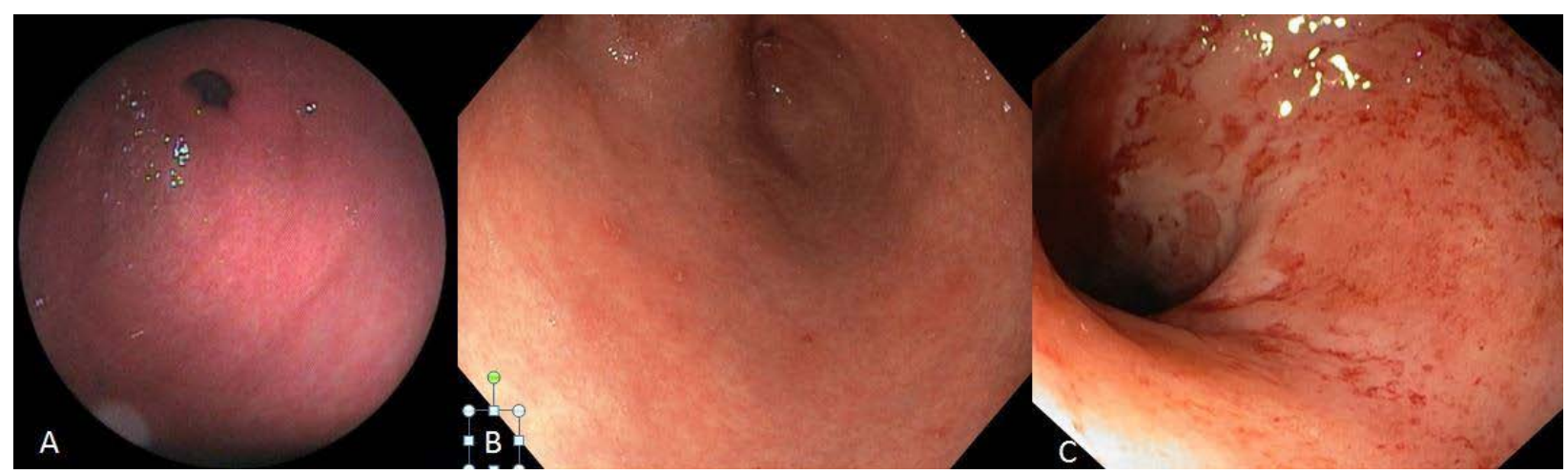

Figure 7: Gastros copy images showing Normal mucosa (A), Mucosa in Mild Acute Gastritis (B) and Mucosa in Erosive Gastritis (C)

\section{Discussion}

Histologically Stomach has four layers, Mucosa, Submucosa, Muscularis Externa and Serosa. Mucosa has three components-Surface epithelium, lamina propria and muscularis mucosa.

Muscularis Propria or Externa has an oblique layer, circular layers and longitudinal layers. ${ }^{3}$

On ultrasound, Gastric wall delineates five distinct layers from within outwards.

From the luminal side- First inner hyper echoic layer, Second inner hypoechoic layer,
Third middle hyper echoic layer, Fourth outer hypo echoic layer and Fifth outermost hyperechoic layer.

From lumen to serosa,

1) The first Echogenic layer represents the interphase between luminal content and the mucosa.

2) The second Hypoechoic layer is due to muscularis mucosa.

3) The third hyperechoic layer is due to Submucosa, which contains Fat and Connective tissue,

4) The fourth Hypoechoic layer is due to muscularis propria or externa, which is composed of muscles. 5) The fifth Hyperechoic layer is due to serosa. 
The first and fifth layers represent interphases.

Individual layer thicknessas follows-

Normal thickness of various gastric layers were

The total wall thickness of 6-7 mm

$\mathrm{S} 1-$ Hyperechoic layer, Mucosa-1 mm.

S2-Hypoechoic layer, Muscularis mucosa-1 mm.

S3-Hyperechoic layer, Submucosa-2-2.5 mm.

S4-Hypoechoic layer, Muscularis propria, $2 \mathrm{~mm}$.

S5-Hyperechoic layer, Serosa, $1 \mathrm{~mm}^{3}$

Layer 1 and 2 represent Mucosa.

Erosion is restricted to the Mucosa, hence layers one and two are involved.

In Ulcer, sub mucosa has to be involved, hence layer 3 is disrupted.

A penetrating Ulcer may extend up to Serosa, in cases of impending perforations. Hence all five layers are involved. ${ }^{3}$

Gastritis can be acute and chronic. Acute gastritis can be mild and severe. In mild Acute Gastritis, the surface epithelium is intact. The mucosa is hyperaemic, oedematous, congested and red. Histologically, there are intraepithelial and intraluminal neutrophils. In severe acute gastritis, there are mucosal erosions with resultant loss of surface epithelium, hemorrhages seen as punctate dark spots with inflammatory and fibrinous purulent exudates. Acute erosive hemorrhagic gastritis is characterized by concurrent erosion and hemorrhages with extensive mucosal damage and is commonly seen in alcoholic and NSAID users. ${ }^{4,5}$

Acute gastritis is caused by $\mathrm{H}$. Pylori, other infectious causes (like bacteria, viruses, fungi and parasites), and non-infective gastritis. Chronic gastritis can be Type A (Autolmmune-Body-fundic predominant), Type B ( $H$. Pylori related-Antral predominant), Type AB (Environmental-Antral-body predominant), Chemical (Reflux-Antral-body predominant) and uncommon forms of gastritis. . $^{-8}$

In Patients of Mild Acute Gastritis, there is a thickening of layer 2 and total gastric wall thickness, on ultrasound. The ratio of the thickness of Layer 2 to total Gastric wall thickness is significant. ${ }^{9}$

Our observations indicate that transabdominal Ultrasound with Convex Probe, followed by Linear Probe, can predict diagnosis of Mild Gastritis and can reduce the number of Endoscopic Evaluations and further Ulcer formations. It can predict associated mucosal erosions if Layer 1 thickness is less than $1 \mathrm{~mm}$ with associated thickening of layer 2. In our case series, 5 cases of gastric erosions were detected on Ultrasound and were confirmed on gastroscopy.

Though Gastroscopy is Gold standard, Ultrasound can be used as a screening modality in the detection of Mild Acute gastritis. It is extremely useful, especially in Paediatric Age group and in Bed ridden patients. It is extremely useful in those individuals who are reluctant to undergo gastroscopy. However, endoscopy, even though invasive, has specific advantages of detection of Reflux Oesophagitis, Hiatus Hernia and extent of erosions, the status of entire gastric mucosa and duodenal bulb and most important it can obtain mucosal Biopsies. ${ }^{9}$

\section{LIMITATIONS}

Gastric wall thickness differs with age, weight, sex, height and smoking and drinking habits.

Reference values of whole Stomach wall thickness and thickness of individual layers vary with diet and ethnicities. The thickness of the gastric wall can be influenced by muscular contractions in the gastric body and antrum. ${ }^{10}$

Further study with larger patient populations and control studies is needed for accurate interpretation of Sonographic findings of gastritis.

The small number of control and patients is the main limitation of this study. Due to this restriction, interpretation should be done with caution. However, our study increases awareness of Ultrasound clues and the diagnosis of gastritis.

\section{Vil. Conclusion}

Our Results suggest that Trans Abdominal Ultrasound with the Convex Probe followed by a Linear Probe, is an excellent Noninvasive Modality in the detection of various layers of Gastric wall, detection of thickening of individual layers in Acute Gastritis. Thus, it is useful in the Diagnosis of Mild Acute Gastritis, thereby probably avoiding invasive procedures, like Gastroscopy and interventions like biopsies.

It can be used as a screening method in the detection of Acute Gastritis, as it is readily available, less time consuming, cheaper, non-invasive, can be done in all age groups (Paediatric to Elder), can be done as bedside procedures and free from Radiation and can be repeated multiple times.

\section{References Références Referencias}

1. Talley N J. Dyspepsia and non-ulcer dyspepsia: an historical perspective. Medical Journal of Australia. 1986 Dec; 145 (11-12): 614-8.

2. Szabo I L, Cseko K, Czimmer J, Mozsik G. Diagnosis of Gastritis-Review from Early Pathological Evaluation to Present Day Management. In Current Topics in Gastritis 2012 (p. 19).

3. Lim J H, Jeong $Y M$ M. Sonography of the stomach: an in vitro study to determine the anatomic cause of inner hyperechoic and hypoechoic layers of the gastric wall. AJR. American journal of roentgenology. 1994 Feb; 162 (2): 335-8. 
4. Sepulveda A R, Patil M. Practical approach to the pathologic diagnosis of gastritis. Archives of pathology and laboratory medicine. 2008 Oct; 132 (10):1586-93.

5. Rugge M, Pennelli G, Pilozzi E, Fassan M, Ingravallo G, Russo VM, Di Mario F. Gastritis: the histology report. Digestive and Liver Disease. 2011 Mar 1; 43: S373-84.

6. Sipponen P, Price AB. The Sydney System for classification of gastritis 20 years ago. Journal of Gastroenterology and Hepatology. 2011 Jan; 26: 31-4.

7. Dixon MF, Genta RM, Yardley JH, Correa P. Classification and grading of gastritis: the updated Sydney system. The American journal of surgical pathology. 1996 Oct 1; 20 (10): 1161-81.

8. Whitehead R. The classification of chronic gastritis: current status. Journal of clinical gastroenterology. 1995; 21: S131-4.

9. Cakmakci E, Ucan B, Colak B, Cinar HG. Novel sonographic clues for diagnosis of antral gastritis and Helicobacter pylori infection: a clinical study. Journal of Ultrasound in Medicine. 2014 Sep; 33 (9): 1605-10.

10. Nylund K, Hausken T, Ødegaard S, Eide GE, Gilja $\mathrm{OH}$. Gastrointestinal wall the thickness measured with transabdominal ultrasonography and its relationship to demographic factors in healthy subjects. Ultraschall in der Medizin-European Journal of Ultrasound. 2012 Dec; 33 (07): E225-32. 